\title{
Pengaruh Motivasi kerja terhadap Kinerja Pegawai pada Dinas Tenaga Kerja dan Transmigrasi Provinsi Sulawesi Selatan
}

\section{The Effect of Work Motivation on Employee Performance at the Office of Manpower and Transmigration of South Sulawesi Province}

\author{
Nursyam $^{1}$, Dita Rahmawati ${ }^{2}$ \\ Akuntansi, Universitas Indonesia Timur \\ 1adhenursyam07@gmail.com) \\ 2(dhitarahma.dr@gmail.com)
}

\begin{abstract}
ABSTRAK
Motivasi kerja merupakan hal penting dalam kehidupan sebuah instansi ataupun perusahaan sebab dengan motivasi yang optimal aan menghasilkan kinerja yang maksimal, untuk mendorong motivasi kerja dapan menciptaan lingkungan kerja yang baik dan sehat, Dinas Tenaga Kerja dan Transmigrasi Provinsi Sulawesi Selatan Kota Makassar merupakan instansi pemerintah yang menangani masalah ketenagakerjaan, secara umum memberikan pelayanan kepada masyarakat. Maka segala bentuk masalah atau hambatan kerja yang ada harus ditangani lebih tepat agar kredibilitas Dinas Tenaga Kerja dan Transmigrasi Provinsi Sulawesi Selatan tetap terjaga. Penelitian ini bertujuan untuk mengetahui Pengaruh Motivasi kerja terhadap Kinerja Pegawai pada Dinas Tenaga Kerja dan Transmigrasi Provinsi Sulawesi Selatan. Penelitian ini bersifat kausalitas dimana pengukuran variabel-variabel penelitian dalam bentuk angka dan melakukan analisis dalam bentuk statistik. Pendekatan penelitian ini melalui beberapa tahapan yakni mengumpulkan data melalui angket atau kuesioner, menganalisis data, dan pengujian hipotesis. Tujuannya untuk mengetahui pengaruh motivasi kerja terhadap kinerja pegawai pada Dinas Tenaga Kerja dan Transmigrasi Provinsi Sulawesi Selatan.populasi dalam penelitian ini adalah pegawai di Dinas Tenaga Kerja dan Transmigrasi Provinsi Sulawesi Selatan berjumlah 207 orang. pengambilan sampel menggunakan rumus Slovin sejumlah 67 pegawai. Teknik pengumpulan data observasi dan quisioner, dengan pengujian regresi linear sederhana. variable motivasi kerja berpengaruh terhadap kinerja pegawai Dinas Tenaga Kerja dan Transmigrasi Provinsi Sulawesi Selatan. Kerja dan Transmigrasi Provinsi Sulawesi Selatan.
\end{abstract}

Kata Kunci : Motivasi kerja, kinerja pegawai, hambatan kerja, lingkungan kerja

\section{ABSTRAK}

Work motivation is important in the life of an agency or company because with optimal motivation to produce maximum performance, to encourage work motivation to create a good and healthy work environment, the Office of Manpower and Transmigration of South Sulawesi Province, Makassar City is a government agency that handles manpower issues, in general providing services to the community. So all forms of work problems or obstacles that exist must be handled more precisely so that the credibility of the South Sulawesi Provincial Manpower and Transmigration Office is maintained. This study aims to determine the effect of work motivation on employee performance at the Manpower and Transmigration Office of South Sulawesi Province. This research is causality in which the measurement of research variables is in the form of numbers and analyzes in the form of statistics. This research approach takes several stages, namely collecting data through a questionnaire or questionnaire, analyzing data, and testing hypotheses. The aim is to determine the effect of work motivation on employee performance at the Office of Manpower and Transmigration of South Sulawesi Province. The population in this study was 207 employees at the Manpower and Transmigration Office of South Sulawesi Province. Sampling using the Slovin formula with a total of 67 employees. Observation and questionnaire data collection techniques, with simple linear regression testing. work motivation variable affects the performance of the employees of the Department of Manpower and Transmigration of South Sulawesi Province. Work and Transmigration of South Sulawesi Province.

Keywords: Work motivation, employee performance, work barriers, work environment 


\section{PENDAHULUAN}

Memotivasi pegawai bukanlah hal yang mudah, karena manusia mempunyai perilaku yang berbeda antara satu dengan yang lainnya dalam memenuhi kebutuhan dan harapannya. Motivasi kerja pegawai merupakan keinginan dalam diri seseorang yang menyebabkan orang tersebut bertindak. Tanpa motivasi, seorang pegawai tidak dapat memenuhi pekerjaannya sesuai standar karena apa yang menjadi motivasi bekerja tidak terpenuhi. Sekalipun seseorang memiliki kemampuan bekerja yang tinggi tetapi tidak memiliki motivasi untuk menyelesaikan tugasnya maka hasil akhir dalam pekerjaanya tidak maksimal.

Terdapat tiga unsur yang merupakan kunci dari motivasi yaitu upaya, tujuan organisasi, dan kebutuhan. Jadi motivasi dalam hal ini merupakan respon dari suatu aksi. Motivasi muncul dalam diri manusia karena dorongan oleh adanya unsur suatu tujuan. Tujuan ini menyangkut soal kebutuhan dapat dikatakan bahwa tidak akan ada suatu motivasi apabila tidak dirasakan adanya suatu kebutuhan. Adanya motivasi kerja yang terdapat dalam diri pegawai yang disertai kinerja yang baik merupakan dua aspek yang sangat diharapkan oleh inst ansi. Sehingga keberhasilan prodiktivitas kerja dapat tercapai.

Motivasi kerja merupakan hal penting dalam kehidupan sebuah instansi ataupun perusahaan sebab dengan motivasi yang optimal aan menghasilkan kinerja yang maksimal, untuk mendorong motivasi kerja dapan menciptaan lingkungan kerja yang baik dan sehat, menurut Mardiana(2009), mengemukakan bahwa lingkungan merupakan salah satu factor yang dapat meningkatkan motivasi karyawan dalam bekerja. Motivasi dapat dikatan sebagai energi untuk membangkitkan dorongan dalam diri. Dalam hubungannya dengan motivasi kerja, Ernest J.Mc Ccormick (1985:1985) yang dikutip Mangkunegara (2009:94) mengemukakan bahwa "work motivation is defined as condition which influensethe arousal, direction and maintenance of behaviors relevan in work settings",motivasi kerja didefinisikan sebagai kondisi yang berpengaruh membangkitkan, mengarahkan dan memelihara perilaku yang berhubungan dengan lingkungan kerja.

Penelitian terdahulu yang dilakukan oleh Ishak (2016) dengan judul "Pengaruh Motivasi Kerja Terhadap Kinerja Pegawai Koperasi berkat Kabupaten Sidrap" hasil penelitiannya menunjukkan bahwa motivasi berpengaruh signifikan terhadap peningkatan kinerja pegawai koperasi akan tetapi memiliki kecenderungan untuk berpengaruh positif, apabila motivasi ditingkatkan secara optimal maka hasil kinerja pegawai akan meningkat. Hal ini disebabkan karena harapan-harapan pegawai telah terpenuhi dengan baik, seperti adanya dorongan-dorongan dari atasan untuk mengembangkan diri, adanya insentif diluar gaji pokok yang relativ sering diterima, dan adanya hubungan harmonis antara sesama pegawai pada unit kerja tersebut.

Selain itu, hasil penelitian dari Dillah(2017) dengan judul "Pengaruh Motivasi Kerja Dan Pemberian Insentif Terhadap Kinerja Pegawai (Studi Kasus Pada Kantor Kelurahan Lingkup Kecamatan Mandonga Kota Kendari)" hasil penelitiannya menemukan bahwa Motivasi Kerja berpengaruh positif dan signifikan terhadap kinerja pegawai pada Kantor Keluran Lingkup Kecamatan Mandonga Kota Kendari. Artinya semakin baik motivasi kerja yang dimiliki oleh pegawai maka akan memberikan kinerja yang baik pula. Selain itu, pemberian insentif berpengaruh signifikan terhadap kinerja pegawai. Jadi, motivasi kerja dan pemberian insentif berpengaruh signifikan terhadap kinerja pegawai pada Kantor Kelurahan Lingkup Kecamatan Mandonga, artinya secara bersama-sama motivasi kerja dan pemberian insentif dapat mempengruhi kinerja pegawai.

Kedua hasil penelitian tersebut, dapat dipahami bahwa apapun yang menjadi kebutuhan pegawai dapat terpenuhi lalu 
diharapkan para pegawai dapat bekerja dengan baik dan merasa senang dengan semua tugas yang diembannya. Setelah pegawai merasa senang dengan pekerjaanya, para pegawai akan saling menghargai hak dan kewajiban sesama pegawai sehingga terciptalah suasana kerja yang kondusif, pada akhirnya pegawai dengan bersungguh-sungguh memberikan kemampuan terbaiknya dalam menjalankan tugas dan tanggung jawab. Dapat dipahami bahwa semakin tinggi pemberian motivasi pegawai dalam bekerja, maka kinerja yang dihasilkan juga baik. Dengan adanya motivasi yang tepat para pegawai akan terdorong untuk berbuat semaksimal mungkin dalam melaksanakan tugasnya. Melihat pentingnya motivasi dan kinerja pegawai, maka dalam hal ini Kantor Dinas Tenaga Kerja dan Transmigrasi Kota Makassar juga perlu memperlihatkan hal tersebut agar dapat meningkatkan produktivitas kerja para pegawainya.

Dinas Tenaga Kerja dan Transmigrasi Provinsi Sulawesi Selatan Kota Makassar merupakan instansi pemerintah yang menangani masalah ketenagakerjaan, secara umum memberikan pelayanan kepada masyarakat. Maka segala bentuk masalah atau hambatan kerja yang ada harus ditangani lebih tepat agar kredibilitas Dinas Tenaga Kerja dan Transmigrasi Provinsi Sulawesi Selatan tetap terjaga. Dari hasil survei awal ditemukan bahwa kinerja pegawai masih belum optimal di Dinas Tenaga Kerja dan Transmigrasi Provinsi Sulawesi Selatan. Adanya kendala yang timbul yaitu masih rendahnya pemahaman fungsi dari sebagian pegawai dalam mendukung pelaksanaan tugas -tugas yang ada. Hal ini dapat dilihat seperti ketidak tepatan waktu masuk dan cepat pulang. Kinerja pegawai perlu mendapat perhatian utama guna mencapai efektif dan efesiensi organisasi . Sehingga pemberian bentuk motivasi kerja dan kemampuan pimpinan dalam mengarahkan, memahami serta memotivasi kerja pegawai dalam menjalankan tugas dan pekerjaannya untuk meningkatkan kinerja guna mencapai kinerja yang lebih baik lagi.

Setiap pegawai dalam organisasi dituntut untuk memberikan kontribusi positif melalui kinerja yang baik, mengingat kinerja organisasi tergantung pada kinerja pegawainya (Gibson et all, 1995:364). Istilah kinerja berasal dari kata Job performance yang artinya hasil kerja secara kuantitas yang dicapai oleh seorang pegawai dalam melaksanakan tugasnya sesuai dengan tanggung jawab yang diberikan kepadanya. Seperti yang diungkapkan oleh Mangkunegara (2017:9) bahwa kinerja karyawan (prestasi kerja) adalah hasil kerja secara kualitas dan kuantitas yang dicapai oleh seseorang karyawan dalam melaksanakan tugasnya sesuai dengan tanggung jawab yang diberikan kepadanya.

Menurut Whitmore dalam Hamzah dan Nina (2014:61) kinerja adalah suatu perbuatan, suatu prestasi, atau apa yang diperlihatkan seseorang melalui keterampilan nyata. King dalam Hamzah dan Nina (2014:61) menyatakan kinerja adalah aktivitas seseorang dalam melaksanakan tugas pokok yang dibebankan kepadanya.

Bernadin dalam Sudarmanto (2015:8) menyatakan bahwa kinerja merupakan catatan hasil yang diproduksi (dihasilkan) atas fungsi pekerjaan tertentu atau aktivitas-aktivitas selama periode waktu tertentu. Dalam hal ini pegawai adalah orang yang melakukan pekerjaan dengan mendapatkan imbalan jasa berupa gaji dan tunjangan dari pemerintah. Pegawai inilah yang mengerjakan segala pekerjaan atau kegiatan-kegiatan penyelenggaraan pemerintah.

Robert dan Bacal dalam Kaswan (2016:6) menjelaskan bahwa "Performance is the dagree to which an employee contributes to the goals of his or her work unit and company as a result of his her behavior and the application of skills, abilities, and knowledge". Artinya kinerja merupakan tingkat kontribusi yang diberikan pegawai terhadap tujuan pekerjaannya atau unit kerja dan 
perusahaan/organisasi sebagai hasil kerja perilakunya dan aplikasi dari keterampilan, kemampuan, dan pengetahuannya.

Campabell dalam Kaswan (2016:6) mengemukakan bahwa "Job performance represent behaviors employees engage in while at work that contribute to organization goals". Jadi kinerja pegawai menggambarkan perilaku yang dilakukan pegawai selama ditempat kerja memberi kontribusi terhadap tujuan organisasi.

Berdasarkan pendapat para ahli diatas maka penulis dapat simpulkan bahwa kinerja merupakan hasil prestasi atau hasil kerja yang menggambarkan sejauh mana sebuah organisasi telah berhasil mencapai tujuan yang telah ditetapkannya. Selain itu, kinerja pegawi juga menunjukkan seberapa baik prilaku pegawai dalam upaya menciptakan tujuan organisasi.

Kinerja pegawai merupakan tingkat pencapaian atau hasil kerja pegawai dari sasaran yang harus dicapai atau tugas yang hasrus dicapai atau tugas yang harus dilaksanakan sesuai dengan tanggung jawab masing-masing.

Setiap pegawai dalam organisasi dituntut untuk memberikan kontribusi positif melalui kinerja yang baik, mengingat kinerja organisasi tergantung pada kinerja pegawainya (Gibson et all, 1995:364). Istilah kinerja berasal dari kata Job performance yang artinya hasil kerja secara kuantitas yang dicapai oleh seorang pegawai dalam melaksanakan tugasnya sesuai dengan tanggung jawab yang diberikan kepadanya. Seperti yang diungkapkan oleh Mangkunegara (2017:9) bahwa kinerja karyawan (prestasi kerja) adalah hasil kerja secara kualitas dan kuantitas yang dicapai oleh seseorang karyawan dalam melaksanakan tugasnya sesuai dengan tanggung jawab yang diberikan kepadanya.

Menurut Whitmore dalam Hamzah dan Nina (2014:61) kinerja adalah suatu perbuatan, suatu prestasi, atau apa yang diperlihatkan seseorang melalui keterampilan nyata. King dalam Hamzah dan Nina (2014:61) menyatakan kinerja adalah aktivitas seseorang dalam melaksanakan tugas pokok yang dibebankan kepadanya.

Bernadin dalam Sudarmanto (2015:8) menyatakan bahwa kinerja merupakan catatan hasil yang diproduksi (dihasilkan) atas fungsi pekerjaan tertentu atau aktivitas-aktivitas selama periode waktu tertentu. Dalam hal ini pegawai adalah orang yang melakukan pekerjaan dengan mendapatkan imbalan jasa berupa gaji dan tunjangan dari pemerintah. Pegawai inilah yang mengerjakan segala pekerjaan atau kegiatan-kegiatan penyelenggaraan pemerintah.

Robert dan Bacal dalam Kaswan (2016:6) menjelaskan bahwa "Performance is the dagree to which an employee contributes to the goals of his or her work unit and company as a result of his her behavior and the application of skills, abilities, and knowledge". Artinya kinerja merupakan tingkat kontribusi yang diberikan pegawai terhadap tujuan pekerjaannya atau unit kerja dan perusahaan/organisasi sebagai hasil kerja perilakunya dan aplikasi dari keterampilan, kemampuan, dan pengetahuannya.

Campabell dalam Kaswan (2016:6) mengemukakan bahwa "Job performance represent behaviors employees engage in while at work that contribute to organization goals". Jadi kinerja pegawai menggambarkan perilaku yang dilakukan pegawai selama ditempat kerja memberi kontribusi terhadap tujuan organisasi.

Berdasarkan pendapat para ahli diatas maka penulis dapat simpulkan bahwa kinerja merupakan hasil prestasi atau hasil kerja yang menggambarkan sejauh mana sebuah organisasi telah berhasil mencapai tujuan yang telah ditetapkannya. Selain itu, kinerja pegawi juga menunjukkan seberapa baik prilaku pegawai dalam upaya menciptakan tujuan organisasi.

Kinerja pegawai merupakan tingkat pencapaian atau hasil kerja pegawai dari sasaran yang harus dicapai atau tugas yang hasrus dicapai atau tugas yang harus dilaksanakan sesuai dengan tanggung jawab masing-masing. 


\section{METODE}

Penelitian ini bersifat kausalitas dimana pengukuran variabel-variabel penelitian dalam bentuk angka dan melakukan analisis dalam bentuk statistik. Pendekatan penelitian ini melalui beberapa tahapan yakni mengumpulkan data melalui angket atau kuesioner, menganalisis data, dan pengujian hipotesis. Tujuannya untuk mengetahui pengaruh motivasi kerja terhadap kinerja pegawai pada Dinas
Tenaga Kerja dan Transmigrasi Provinsi Sulawesi Selatan..

populasi dalam penelitian ini adalah pegawai di Dinas Tenaga Kerja dan Transmigrasi Provinsi Sulawesi Selatan berjumlah 207 orang. pengambilan sampel menggunakan rumus Slovin sejumlah 67 pegawai. Teknik pengumpulan data observasi dan quisioner. Dengan pengujian regresi sederhna

Table 1. Uji Hipotesis

\begin{tabular}{lcccccc}
\hline \multicolumn{1}{l}{ Model } & Sum of Squares & df & Mean Square & F & Sig. \\
\hline \multirow{2}{*}{$\mathbf{1}$} & Regression & 367.585 & 1 & 367.585 & 96.693 & $.000^{\mathrm{b}}$ \\
\cline { 2 - 6 } & Residual & 247.102 & 65 & 3.802 & & \\
\cline { 2 - 7 } & Total & 614.687 & 66 & & & \\
\hline
\end{tabular}

a. Dependent Variable : kinerja pegawai

b. Predictors: (Constant), motivasi kerja

Sumber: Data Primer Diolah, 2020

Berdasarkan hasil tabel data diatas diketahui bahwa nilai signifikansi (sig) variable motivasi kerja adalah 0,000. Karena nilai sig $0,000<$ nilai probabilitas 0,005, maka dapat disimpulkan bahwa variable motivasi kerja berpengaruh terhadap kinerja pegawai Dinas Tenaga Kerja dan Transmigrasi Provinsi Sulawesi Selatan. Dengan demikian hipotesis yang diterima dalam penelitian ini adalah $\mathrm{H} 1$ yang menyatakan bahwa terdapat pengaruh motivasi kerja terhadap kinerja pegawai Dinas Tenaga Kerja dan Transmigrasi Provinsi Sulawesi Selatan.

Hasil perhitungan determinasi diketahui bahwa besarnya nilai korelasi atau hubungan (R) yaitu sebesar 0,773. Besarnya nilai $\mathrm{R}$ square adalah 0,598 yang mengandung pengertian bahwa variable kinerja pegawai berpengaruh sebesar 77,3\% Dinas Tenaga Kerja dan Transmigrasi Provinsi Sulawesi Selatan. Sedangkan sisanya sebesar 22,7\% dipengaruhi oleh faktor lain yang tidak diteliti didalam penelitian ini.
Uji hipotesis dalam penelitian ini didapatkan nilai signifikansi (sig) variable pengembangan SDM adalah 0,000. Karena nilai sig $0,000<$ nilai probabilitas 0,005, maka dapat disimpulkan bahwa variable motivasi kerja berpengaruh terhadap kinerja pegawai Dinas Tenaga Kerja dan TransmigrasiProvinsi Sulawesi Selatan. Dengan demikian hipotesis yang diterima dalam penelitian ini adalah $\mathrm{H} 1$ yang menyatakan bahwa terdapat pengaruh motivasi kerja terhadap kinerja pegawai Dinas Tenaga Kerja dan Transmigrasi Provinsi Sulawesi Selatan.

Hasil penelitian ini sesuai dengan penelitian yang dilakukan oleh Rido Sanjaya (2018) yang melakukan penelitian dengan judul penelitian pengaruh motivasi kerja terhadap kinerja pegawai dalam perspektif ekonomi islam (Studi Di Dinas Sosial Tenaga Kerja Dan Transmigrasi Kabupaten Pesisir Barat). Hasil penelitian menunjukkan bahwa motivasi kerja berpengaruh secara signifikan terhadap kinerja pegawai, dimana Kepala Dinas 
sebagai pimpinan mempunyai peran untuk memotivasi. Hal tersebut dibuktikan berdasarkan hasil perhitungan secara regresi sederhana menunjukkan bahwa tingkat $\mathrm{t}$ hitung pada variable motivasi kerja sebesar $(3,557)>2,045$. Menandakan bahwa $t_{\text {hitung }}>t_{\text {tabel }}$ sehingga dapat disimpulkan bahwa $\mathrm{HO}$ ditolak dan Ha diterima dengan arti bahwa motivasi kerja berpengaruh secara signifikan terhadap kinerja pegawai. Dan koefisien determinasi sebesar 0,306 yang artinya pengaruh motivasi kerja terhadap kinerja pegawai $30.6 \%$ sedangkan sisanya $69,4 \%$ dipengaruhi oleh faktor lain yang tidak diteliti pada penelitian yang dilakukan. Hal ini menunjukkan semakin kuat motivasi, kinerja pegawai akan semakin tinggi. Dimana setiap peningkatan motivasi akan memberikan peningkatan yang sangat berarti bagi peningkatan kinerja pegawai. Arti signifikan memiliki arti bahwa tingkat motivasi sangat berpengaruh terhadap kinerja pegawai.

Perbedaan penelitian yang dilakukan oleh Rido Sanjaya (2018) adalah terletak pada lokasi penelitian yaitu pada instansi Dinas Tenaga Kerja dan Transmigrasi Provinsi Sulawesi Selatan dengan hasil nilai determinasi yang lebih tinggi sebesar 0,598 yang mengandung pengertian bahwa variable kinerja pegawai berpengaruh sebesar 59,8\%. Serta waktu penelitian dilaksanakan pada saat menghadapi pandemi Covid - 19.

\section{KESIMPULAN DAN SARAN}

Motivasi kerja berpengaruh terhadap kinerja pegawai Dinas Tenaga Kerja dan Transmigrasi Provinsi Sulawesi Selatan dengan hasil Signifikansi. Adapun sisanya dipengaruhi oleh faktor lain yang tidak diteliti didalam penelitian ini. Dengan demikian Hipotesis yang diterma dalam penelitian ini adalah $\mathrm{H} 1$ yang menyatakan terdapat pengaruh motivasi kerja terhadap kinerja pegawai Dinas Tenaga Kerja dan Transmigrasi Provinsi Sulawesi Selatan.

Guna meningkatkan motivasi dalam kinerja pegawai diharapkan pihak Kantor Dinas Tenaga Kerja dan Transmigrasi Provinsi Sulawesi Selatan memperhatikan lagi bentuk motivasi kerja pegawai seperti prestasi, karena apabila pegawai merasa termotivasi dalam pekerjaannya maka kinerja juga akan lebih baik, dengan cara pimpinan lebih meningkatkan pemberian penghargaan kepada pegawai yang memiliki kemampuan dan memiliki prestasi. Tingginya motivasi kerja yang membuat pegawai nyaman dan sigap dalam mengerjakan tugasnya.

\section{UCAPAN TERIMAKASIH}

Ucapan terimakasih kepada pihak terkait baik langsung maupun tidak sampai penelitian ini selesai dan dapat kami publikasikan.

\section{DAFTAR PUSTAKA (12, bold)}

Afrizal. 2016. Metode Penelitian Kualitatif. Jakarta: PT Raja Grafindo Persada

Aksari H, Andi Winda. 2018. Pengaruh Motivasi Terhadap Kinerja Pegawai pada Kantor Dinas Tenaga Kerja Kota Makassar. Universitas Negeri Makassar, 2018

Airulmukminin, A. 2020. The Effect Of Work Discipline and Work Motivation on Employee Performance at UPT Puskesmas Ambalawi District. Economy Deposit Journal (E-DJ), 2(1), 1118

Arikunto, Suharmisi.2006. Prosedur Penelitian Suatu Pendekatan Praktek. Jakarta: Rieneka Cipta

Aqfir, A., \& Suriani, S. (2019). Influence Of Leadership, Competence And Career Development Againstimprovement In The Employee 
Performancedepartment Of Finance And Accounting Pt. Hardaya Inti Plantations Buol. Economy Deposit Journal (E-DJ), 1(2), 1-7.

Burhanuddin, B., \& Samsidar, S. (2019). Influence of Motivation on Employee Performance in PT. Seafood Nusantara District, Tolitoli. Economy Deposit Journal, 1(2), 55-63.

Chrisnanda, Dody. 2017. Pengaruh Motivasi Kerja Terhadap Kinerja Karyawan di PT. Mas Sumbiri. Universitas Sanata Dharma, 2017

Dillah, Fatma Farah. 2017. Pengaruh Motivasi Kerja dan Pemberian Insentif Terhadap Kinerja Pegawai (Studi Kasus pada Kantor Kelurahan Lingkup Kecamatan Mandonga Kota Kendari). Universitas Halu Oleo Kendari, 2017

Elva, Dona. 2013. Analisis Motivasi Kerja Ditinjau Dari Lingkungan kerja Kasus Karyawan LBPP LIA Payakumbuh. Jurnal KBP. Volume 1-No. 3

Hamzah \& Nina. 2014. Teori Kinerja dan Pengukurannya. Jakarta: Rineka Cipta

Hamid, R. (2019). Analisis Pengaruh Motivasi Terhadap Kinerja Pegawai Rumah Sakit Angkatan Laut Jala Ammari Makassar. Economy Deposit Journal (E-DJ), 1(1), 49-54.

Ishak, Widiastuti. 2016. Pengaruh Motivasi terhadap Kinerja Pegawai Koperasi Berkat Kabupaten Sidrap. Universitas Negeri Makassar, 2016
Kaswan. 2016. Peak Performance. Bandung: Alfabeta

Mangkunegara, Anwar Prabu. 2015. Manajemen Sumber Daya Manusia Perusahaan. Bandung: PT Remaja Rosdakarya

2017. Evaluasi kinerja. Bandung: PT Refika Aditama

Mulyadi. 2015. Manajemen Sumber Daya Manusia (MSDM). Jakarta: In Media

$\begin{array}{ccc}\text { Notoatmodjo, } & \text { Soekidjo. } & 2015 . \\ \text { Pengembangan } & \text { Sumber } & \text { Daya } \\ \text { Manusia. Jakarta: } & \text { Rineka Cipta }\end{array}$

Patawari, P., \& Nongkeng, H. (2019). Pengaruh Gaya Kepemimpinan Kepala Sekolah dan Lingkungan Kerja Sekolah terhadap Motivasi Kerja Guru MA Ihya'Ulumiddin Kampung Beru Kabupaten Bantaeng. Economy Deposit Journal (E-DJ), 1(1), 41-48.

Prawirosentono, Suryadi. 1999. Kebijakan Kinerja Karyawan. Yogyakarta: BPFE

Rumpak, Aristaskus Didimus. 2014. Pengaruh Motivasi Kerja Terhadap Kinerja Karyawan pada Bank Indonesia. Institute Bisnis dan Multimedia Asmi

Sanjaya, Rido. 2018. Pengaruh Motivasi Kerja Terhadap inerja Pegawai dalam Perspektif Ekonomi Islam (Studi di Dinas Sosial Tenaga Kerja dan Transmigrasi Kabupaten Pesisir Barat). UIN Raden Intan Lampung, 2018

Sanusi, Anwar. 2011. Metode Penelitian Bisnis, Salemba Empat. Jakarta 
Sutrisno, Edy. 2009. Manajemen Sumber

Daya Manusia. Jakarta: Prenada Media

\begin{tabular}{lll}
\multicolumn{2}{c}{.2010. } & Budaya \\
\hline $\begin{array}{l}\text { Organisasi. } \\
\text { Media Group }\end{array}$ & Jakarta: & Prenada
\end{tabular}

Sedarmayanti. 2016. Manajemen Sumber Daya Manusia. Bandung: PT Refika Aditama

Sudarmanto. 2015. Kinerja dan Pengembangan Kompetensi SDM. Yogyakarta: Pustaka Belajar

Wibowo. 2016. Manajemen Kinerja. Jakarta: PT Raja Grafindo Persada

Yenni. 2019. Pengaruh Motivasi Kerja Terhadap Kinerja Pegawai. Jurnal Menata. Volume 2, No. 2 